\title{
Água como bem econômico: dessalinização para o combate da escassez hídrica no agronegócio
}

Water as an economic good: desalination to combat water scarcity in agribusiness

Agua como bien económico: desalinización para el combate de la escasez hídrica en el agronegócio

Valesca Schardong Villes ${ }^{1}$ João Pedro Velho Luciana Fagundes Christofari ${ }^{3}$ Rafael Lazzari ${ }^{4}$

${ }^{1}$ Bióloga pela Universidade Federal de Santa Maria (UFSM). Discente do Programa de Pós-Graducação em Agronegócios, da UFSM. Bolsista Capes/Brasil. E-mail: valesca_villes@hotmail.com, Orcid: http://orcid.org/0000-0002-1492-6942

${ }^{2}$ Doutor em Zootecnia pela Universidade Federal do Rio Grande do Sul (UFRGS). Zootecnista pela Universidade Federal de Santa Maria (UFSM). Professor Associado I, Departamento de Zootecnia e Ciências Biológicas na UFSM. E-mail: velhojp@ufsm.br, Orcid: http://orcid.org/0000-0003-3901-8200

${ }^{3}$ Doutora em Zootecnia e Médica Veterinária pela Universidade Federal do Rio Grande do Sul (UFRGS). Professora Associada I, Departamento de Zootecnia e Ciências Biológicas na Universidade Federal de Santa Maria (UFSM). E-mail: luciana_christofari@ufsm.com, Orcid: http://orcid.org/0000-0002-7637-3423

${ }^{4}$ Doutor em Zootecnia e Zootecnista pela Universidade Federal de Santa Maria (UFSM). Professor Associadoll, Departamento de Zootecnia e Ciências Biológicas na UFSM. E-mail: rlazzari@ufsm.br, Orcid: http://orcid.org/0000-0003-3016-6215 
Resumo: A água é um dos principais recursos naturais que geram vida e, por estar envolvida em todos os setores do agronegócio, vem se tornando objeto de atenção por sua limitada disponibilidade no planeta. Sob a pressão do crescimento populacional e desenvolvimento econômico, ocorrerá uma forte demanda pela água nessa área. A crise hídrica mundial, associada às grandes exigências do setor agrícola com a tecnologia disponível, traz a viabilidade e o benefício da implementação de projetos alternativos de usinas dessalinizadoras. Sendo assim, com o artigo, objetivou-se analisar o processo de dessalinização como alternativa ao combate da carência hídrica no agronegócio, por meio de uma análise descritiva em pesquisa bibliográfica. O desenvolvimento de tecnologias com o intuito de reduzir os impactos ambientas e os custos de investimento e de produção, tornará essa técnica sustentável para garantir as exigências da água potável para a populaçao mundial futura e atual.

Palavras-chave: recurso hídrico; dessalinizadora; tecnologia; agricultura.

Abstract: Water is one of the main natural resources that generates life and being involved in all the sectors of the agribusiness, has become object of attention due to its limited availability in the planet. Under the pressure of population growth and economic development there will be a strong demand for water in this area. The global water crisis associated with the great demands of the agricultural sector with the available technology, brings the viability and benefit of the implementation of alternative projects of desalination plants. Thus, the article aimed to analyze the desalination process as an alternative to the water deficit in agribusiness, through a descriptive analysis in bibliographical research. The development of technologies to reduce environmental impacts and the costs of investment and production will make this technique sustainable to ensure the requirements of drinking water for the future and current world population.

Keywords: water resources; desalination; technology; agriculture.

Resumen: El agua, es uno de los principales recursos naturales que generan vida y por estar involucrada en todos los sectores del agronegocio, viene siendo objeto de atención por su limitada disponibilidad en el planeta. Bajo la presión del crecimiento poblacional y el desarrollo económico ocurrirá una fuerte demanda por el agua en esta área. La crisis hídrica mundial asociada a las grandes exigencias del sector agrícola con la tecnología disponible, trae la viabilidad y el beneficio de la implementación de proyectos alternativos de plantas desalinizadoras. Siendo así, con el artículo se objetivó analizar el proceso de desalinización como alternativa al combate de la carencia hídrica en el agronegocio, por medio de un análisis descriptivo en investigación bibliográfica. El desarrollo de tecnologías con el fin de reducir los impactos ambientales y los costos de inversión y de producción, hará que esta técnica sea sostenible para garantizar las exigencias del agua potable para la población mundial futura y actual.

Palabras clave: recursos hídricos; desalinización; tecnologia; agricultura. 


\section{INTRODUÇÃO}

Com o aumento populacional, desenvolvimento econômico e padrão de vida elevado da população, em uma configuração crescente de urbanização e industrialização, a demanda pelas cadeias produtivas da agricultura e das agroindústrias estão aumentando, consequentemente exigindo amplos volumes por serviços públicos essenciais e impactando nos recursos naturais em nosso país.

Recentemente, a água tem se tornado objeto de atenção por conta de sua importância e utilização, quanto pela limitada disponibilidade no planeta, sendo um dos principais recursos diretamente ou indiretamente usados para fins econômicos e sociais no agronegócio, incluindo a produção agroindustrial; alimentação e agricultura; geração de energia; navegação e transporte de cargas; atividades relacionadas aos serviços prestados pelos ecossistemas como pesca e lazer; utilização indireta nos aglomerados humanos, como higiene, limpeza, manutenção da casa, diluição de esgotos; tendo a necessidade de garantir a segurança hídrica da população.

O planeta Terra é considerado azul, devido a $70 \%$ de sua superfície estar coberta por água, no entanto essa quantidade não é própria para consumo humano, ou seja, não é potável, e sua distribuição é desigual ao longo do seu território. Em sua maioria, está na forma salgada dos mares e, em minoria, de água doce, concentrada em geleiras, rios, lagos e lençóis subterrâneos. Desse modo, há uma grande quantidade indisponível de água potável no mundo, diretamente associada a um gerenciamento inadequado e superexploração dos recursos hídricos, efeitos provocados pelas mudanças climáticas, pela poluição, desmatamento nas cabeceiras dos rios, acidentes ambientais e contaminação da água perante falta de saneamento básico e por produtos químicos provenientes de atividades agrícolas, descarga de dejetos industriais sem o devido tratamento, utilização de agrotóxicos e fertilizantes, ou pela inacessibilidade aos reservatórios subterrâneos, permanecendo somente uma pequena parcela dessa água destinada ao consumo humano, inserindo incertezas quanto à previsão da disponibilidade futura de água.

Atualmente grande parte da população mundial não possui água potável, bilhões de pessoas estarão vivendo em países ou regiões com escassez 
de água absoluta e utilizando recursos hídricos contaminados. Entende-se, então, que uma significativa parte da população mundial em breve enfrentará algum tipo de dificuldade severa e estará vivendo sob estresse hídrico, o que corresponde um nível de consumo superior à capacidade de renovação local por meios naturais, sendo necessária a inclusão de novos meios de atender a demanda por água.

A geração de novas tecnologias e a gestão de recursos naturais devem evitar desperdícios, visto que, na maior parte no mundo, ela se encontra na forma salgada, e a transformação em água potável pode ser uma saída cada vez mais aceita e pesquisada pelas técnicas de dessalinização. Sendo assim, com o artigo, objetivou-se analisar o processo de dessalinização como alternativa ao combate da carência hídrica no setor do agronegócio.

\section{DESENVOLVIMENTO}

\section{1 Água no agronegócio}

No ano de 1988, a Constituição Brasileira reconheceu o pagamento para uso da água e instituiu a Política Nacional de Recursos Hídricos, pela Lei Federal n. 9433/97 definindo a "água como um recurso natural limitado, dotado de valor econômico", defendendo o uso racional desse bem, reconhecendo a obrigação de preservação para as futuras gerações e a considerando uma commodity incorporada na produção de bens e serviços, o que é relevante em função da abundância e importância desse recurso brasileiro.

A água desempenha um papel extraordinário na economia mundial, devido à observação de que, em todos os produtos comercializados, desde alimentos, peças de vestuário e aparelhos eletrônicos, há um consumo de água que não é demonstrado ao consumidor na embalagem, omitindo o verdadeiro impacto hídrico no agronegócio (OLIVEIRA et al., 2016). Dentre as atividades econômicas do setor de maior relevância, destaca-se a agricultura, como o item com maior demanda de água doce, responsável mundialmente por cerca de $70 \%$ de toda a água disponível principalmente para a irrigação e, no nosso país, esse índice chega a $72 \%$, ressalta a Organização das Nações Unidas (ONU, 2016), corroborando ao Ministério do Meio Ambiente (2006) em que a agricultura do Brasil consome 69\% 
da água dos mananciais, seguida do abastecimento doméstico (21\%) e da atividade industrial (10\%).

A prática agrícola é responsável por cerca de $70 \%$ da utilização da água doce, cuja maioria emprega-se na irrigação de plantações; da porcentagem restante, aproximadamente $22 \%$ são utilizadas pela atividade industrial em seus processos de produção, e $8 \%$ são para uso doméstico, que está diretamente relacionado à quantidade de água retirada por populações em cidades, vilas, conjuntos habitacionais e por empresas que prestam serviços públicos e domésticos (FAO, 2014). Zamberlan (2011) acrescenta que a água tem adquirido relevância no cenário da agricultura irrigada.

A remoção de água para a agricultura atinge $44 \%$ do total nos países da Organização para Cooperação e Desenvolvimento Econômico (OCDE) e aumenta para mais de $60 \%$ nos países da OCDE, que dependem fortemente de agricultura irrigada. Nos países do BRIC (Brasil, Rússia, Índia e China), a agricultura é responsável por $74 \%$ das retiradas de água, mas varia de um valor abaixo de $20 \%$ na Rússia para cerca de 90\% na Índia (FAO, 2014).

\subsection{Processo de dessalinização}

Em tempos recentes, o uso do processo de dessalinização tem se desenvolvido espantosamente em todo o mundo, tanto para produzir água potável por meio de água subterrânea salobra e água marinha, quanto para aprimorar a qualidade de água doce para consumo humano, na irrigação ou uso industrial, além do tratamento de águas residuais derivadas da indústria (PUJATO, 2005).

A dessalinização é definida como um processamento físico-químico, no qual, por meio de um equipamento chamado dessalinizador, ocorre a separação em grande parte dos sais minerais dissolvidos na água salobra, consistindo na retirada de 95 a 98\% dos sais minerais existentes, deixando a água com um teor de sais reduzidos e potável, pronta para o consumo da população (BERTONCINI, 2008), ou seja, efetua a separação em dois fluxos, um com baixa concentração de sais dissolvidos (o fluxo de água potável) e o outro contendo os remanescentes dos sais dissolvidos (o concentrado ou fluxo de salmoura) (SOUZA, 2006). O dispositivo dessalinizador 
é considerado um processador complexo, pois os sais estão fortemente ligados às moléculas da água, o que torna ineficientes as metodologias convencionais de tratamento desta, sendo imprescindíveis procedimentos capazes de romper as forças de atração entre as moléculas da água e dos sais (PEREIRA JÚNIOR, 2005).

A salinidade da água refere-se à quantidade total de sais minerais dissolvidos nesta, e em média, a água dos oceanos tem uma salinidade de cerca de 35.000 ppm, e a água salobra subterrânea, que está naturalmente disponível em muitas regiões, é contaminada com sais dissolvidos em diferentes graus, embora em nível menor do que o mar (SILVA, 2015). Segundo os padrões utilizados pela Organização Mundial da Saúde (OMS), a água que contém concentrações de sais minerais abaixo de 1000 miligramas por litro ( $\mathrm{mg} / \mathrm{L}$ ) é aceitável para o consumo humano e a água salgada não pode ser consumida pelo ser humano podendo causar desidratação, assim como não pode ser usada em indústrias e na agricultura porque, destrói máquinas e afeta plantações.

Na realidade, a dessalinização da água do mar em larga escala é uma alternativa antiga, que remonta à década de 1970 (SOUZA; FERREIRA, 2016), em que navegadores tomaram a natureza como modelo, usando a evaporação solar para separar o sal da água do mar, e esse processo hoje vem se expandindo de forma grandiosa, por estudos para aperfeiçoar o desempenho, segurança, viabilidade econômica das técnicas existentes (SOUZA, 2006; AMORIM et al., 2004), principalmente nas regiões semiáridas e em países onde a água potável é escassa.

Segundo Pereira Junior (2005), a dessalinização é empregada em situações com localidades situadas no litoral, em lugares com água de poço salobra e, em navios, submarinos, plataformas de petróleo e outros que carecem de água potável para suas tripulações. Diante de Oliveira (2013), na região semiárida do nordeste brasileiro, o irregular nível de precipitação no ano, torna o uso da irrigação indispensável para o desenvolvimento da agricultura, optando o uso da tecnologia de dessalinização por Osmose Reversa, para permitir a sua utilização nessa atividade produtora de alimentos.

Hoje em dia, as usinas empregam duas técnicas de dessalinização da água que vêm se mostrando viáveis em larga escala, sendo uma pelo 
processo de Destilação, e a outra por Osmose Reversa. O processo de Destilação trata-se do aquecimento da água do mar em estado líquido em geral combinando painéis solares com a queima de combustíveis para produzir o calor necessário para transformar a água em vapor. Esse vapor passa pelo condensador, onde é resfriado pela própria água do mar que está entrando, resultando na água destilada coletada em outro recipiente, enquanto as partículas sólidas de sal ficam retidas no balão de destilação (PEREIRA JúNIOR, 2005). Ainda, segundo Pereira Júnior (2005), a água destilada, resultado desse processo é água pura, e pode ser usada para diversos fins, principalmente em indústrias e laboratórios, mas é imprópria para o consumo humano, pois ela pode causar graves problemas ao organismo, e, para que ela se torne potável, é necessário adicionar uma determinada quantidade de mistura de sais que, em geral, estão presentes na água doce encontrada na natureza.

O segundo método de dessalinização por Osmose Reversa, consiste em o solvente da solução concentrada passar pela membrana semipermeável de tubos de pequenos diâmetros, construídos com material filtrante, que são imersos na água salobra. A mudança de salinidade da água do reservatório em que estão mergulhados, comparada à do interior dos tubos, exige um sistema de bombeamento capaz de exercer um gradiente na pressão osmótica, permitindo somente a passagem de líquidos, retendo partículas sólidas de sais no reservatório, ou seja, a água salgada ou salobra, que é o meio mais concentrado, se desloca no sentido do menos concentrado que é a água pura, afastando-se dos seus sais, onde a água é reclusa e conduzida para uso (PEREIRA JÚNIOR, 2005).

Ao nível mundial, Osmose Reversa é o procedimento de maior utilização no Brasil (PUJATO, 2005), porém é mais apropriado a ocasiões em que o sal dissolvido na água é relativamente pequeno, como em poços com água salobra, e pouco aplicado para dessalinizar água do mar, devido ao teor muito elevado de sais, o que reduziria espantosamente a vida útil e a ação dos equipamentos, por fim, quanto maior o teor de sal, menor é a resistência das membranas filtrantes, que são confeccionadas do resultado da tecnologia à indústria espacial (PEREIRA JÚNIOR, 2005). Essa técnica é considerada a unidade de purificação de água mais promissora, por ter o processo a 
vantagem de ser simples, com baixo investimento em equipamentos e operação, gerando água de qualidade etc. (PUJATO, 2005), além de ser muito usada para amenizar catástrofes naturais que ocasionam escassez de água potável, como tsunamis, por exemplo, aproveitando navios marinhos para dessalinizar a água salgada, para ser consumida pelas vítimas durante o dia.

\subsection{Viabilidade economia da dessalinização}

Os custos de instalação e de operação de estações dessalinizadoras são elevados, o que, segundo Pereira Júnior (2005), é devido a fatores que exigem que os tubos, bombas e reservatórios sejam construídos em aço inoxidável, pela elevada alcalinidade da água salgada corroer, formar placas salinas e entupir equipamentos, também pela destilação da água estabelecer um elevado consumo de energia e pela complexidade operacional exigir mão de obra especializada.

Estudos realizados sobre a análise e avaliação econômica da dessalinização, encontraram custos de produção de água doce na faixa de U\$0,50/ $\mathrm{m}^{3}$ para plantas de grande capacidade e em alguns locais com condições específicas, enquanto em outras regiões, em condições menos favoráveis, os custos alcançaram na faixa de U\$1,00/m³ (GHAFFOUR; MISSIMER; AMY, 2013), principalmente em situações que exigem elevados custos para transferir a água ou que requerem a construção de barragens, reservatórios ou canais de transferências. Outros estudos, sobre os valores de produção de água utilizando as tecnologias de dessalinização por energia solar como fonte, encontraram custos na faixa de mínimo $U \$ 3 / \mathrm{m}^{3}$, na utilização de água salobra para alimentação, e de máximo $U \$ 27 / \mathrm{m}^{3}$, usando água do mar (ALI; FATH; ARMSTRONG, 2011). Valores internacionais apontam que a água dessalinizada custa cerca de US\$ $0.60 / \mathrm{m}^{3}$ de tarifa operacional e US\$ $2.00 / \mathrm{m}^{3}$ de valor de depreciação ou amortização do equipamento, ou seja, de maneira geral custa US\$3.00/m³ (FREITAS, 2011). O preço de produção de água dessalinizada, está em torno de $U \$ 2,00 / \mathrm{m}^{3}$, em um estudo no Ceará, Paraíba e Rio Grande do Norte, corroborando que a dessalinização só é viável em casos excepcionais, nos quais é impossível obter água doce da própria natureza (PEREIRA JÚNIOR, 2005). 


\subsection{Dessalinização em nível global}

O crescimento da dessalinização aumentou significativamente nos últimos 20 anos, como resultado da busca dos países pelo aumento no abastecimento de água e da redução combinada das cotações de energia e industriais (IRENA, 2012). Segundo o International Desalination Association (IDA, 2017), no mundo inteiro, existem cerca de 17.000 centrais de dessalinização em operação, que produzem um total de mais de 80 milhões $\mathrm{m}^{3} / \mathrm{dia}$ de água potável, abastecendo mais de 300 milhões de pessoas com água dessalinizada, perfazendo 150 países dessalinizadores.

A Arábia Saudita possui a maior capacidade do mundo de produzir água dessalinizada, com sua construção iniciada no começo de 2011 e implantada em 2014, é responsável pela produção de 728.000 m²/dia $(24,4 \%)$, seguida dos EUA (15,2\%), Emirados Árabes (10,6\%), Kuwait (9,1\%) (SOUZA, 2006) e Japão (ARRAIA, 2010). O Oriente Médio detém o primeiro lugar na obtenção de água dessalinizada, com a maior central em expansão localizada em Ashkelon (Israel), sendo a maior instalação de usina dessalinizadora do mundo por Osmose Reversa (LARANJEIRA, 2010), e um dos mais experientes países que reutiliza quase 60\% desse recurso na irrigação (THOMAS; DURHAM, 2003). Outras grandes usinas de dessalinização da água encontram-se no Kuwait, Curaçao, Aruba, Guermesey e Gibraltar, abastecendo-os totalmente com água doce retirada do mar (PEREIRA JÚNIOR, 2005).

O relatório divulgado pela organização britânica Global Water Intelligence (GWI), demonstra o aumento ímpar de 9,5 milhões $\mathrm{m}^{3} /$ dia na produção de água doce no ano de 2011, satisfazendo cerca de 10\% da capacidade de produção global. A Agência Internacional de Energia Renovável (IRENA, 2012) publicou, em seu relatório atual sobre dessalinização e energias renováveis, que dessalinizar é considerado a melhor fonte de água para saciar a sede humana e a irrigação no Oriente Médio, Norte da África e nas ilhas do Caribe. Já perante a empresa Veolia Water Technologies, líder mundial na prestação de serviços relacionados ao tratamento de água e efluentes líquidos, já construiu estações de todos os portes para a dessalinização de água do mar e salobra, em Sidney, na Austrália, atendendo 15\% das necessidades diárias de água da cidade (VEOLIA, s.d.). 
No Brasil, embora o assunto da dessalinização de água ainda seja pouco publicado (SOUZA, 2006), o abastecimento da população por esse meio concentra-se mais na região Nordeste. A usina pioneira para fornecimento público de dessalinização de água de mar, com tecnologia nacional, está localizada em Fernando de Noronha, no estado de Pernambuco, desde abril de 2004, com um investimento de aproximadamente R\$583 mil (PUJATO, 2005), porém outras unidades estão sendo instaladas, sobretudo pelo Programa Água Doce, coordenado pelo Ministério do Meio Ambiente, do Governo Federal. O programa construiu 65 delas para populações de pequenas com unidades com baixa renda do Semiárido, a maioria em Pernambuco, na Paraíba e no Rio Grande do Norte (ARRAIA, 2010), utilizando a técnica de dessalinização por Osmose Reversa. Percebe-se então, que esta é uma alternativa para prover água de qualidade para o consumo humano por meio do aproveitamento sustentável de águas subterrâneas, evidenciando a aplicação de um sistema de gestão que contempla diversos componentes, cujo resultado final permite a alimentação desde a criação de tilápias, de caprinos, ovinos e bovinos, contribuindo para a segurança alimentar das populações atendidas pelo programa (SILVA, 2015). Porém, dentre as dificuldades na implantação dos equipamentos no Nordeste, destaca-se a falta de operações e manutenções adequadas, estimando-se que cerca de $30 \%$ dos equipamentos espalhados em pequenas comunidades com água salobra no estado do Ceará, encontram-se inativos ou operando precariamente, pois os usuários são carentes e dependem de investimento público para restaurar os dessalinizadores (DUBON; PINHEIRO, 2001).

\subsection{Benefícios e malefícios da dessalinização}

Em vista dos impactos respectivos às mudanças climáticas e dos prognósticos socioeconômicos, a dessalinização da água é uma medida para o equacionamento da segurança hídrica com diversos benefícios para abastecer suplementarmente à demanda de água, substituindo perdas de outras fontes, ajudando nas mudanças climáticas, aumentando a simetria e qualidade do abastecimento. Para tanto, é imprescindível no projeto e operação de usinas dessalinizadoras analisar aspectos ambientais e seus 
impactos críticos consequentes, tais como: consumo de energia, impactos ecológicos da água de abastecimento, disposição dos rejeitos, localização da usina e características do ecossistema (PUJATO, 2005), podendo estes serem mitigados no planejamento e medidas de proteção ambiental.

O foco das atenções vai para as fontes de energia que garantirão o funcionamento dessas usinas, que geram emissão de dióxido de carbono, resultando em poluição ambiental (MEZHER et al., 2011) e influenciando os custos de produção; porém o consumo de energia pelas plantas de dessalinização abre perspectivas promissoras para o uso de tecnologias sustentáveis, como energia solar e eólica como insumo, gerando menor impacto ambiental (SILVA, 2015; SOUZA; FERREIRA, 2016).

Esse processo também resulta em dois produtos, um que é a água doce para o consumo humano e suas atividades, outro que é denominado rejeito, com alta concentração de sal, ao qual é preciso oferecer destinação correta (AZEVEDO, 2016), caso contrário, quando despejado sem critério algum ao meio ambiente, pode tornar-se um poluente ambiental, cujo maior impacto é a erosão e salinidade do solo, alterações na fauna e flora do ecossistema aquáticos com diminuição dos níveis de oxigênio. Perante Cooley, Ajami, Heberger (2013), a água residual tem a concentração de sais muito superior à concentração natural no oceano e apresenta resíduos que são tóxicos para os seres marinhos, como aditivos químicos incorporados ao tratamento da água e metais pesados, que são liberados de processos corrosivos dentro das tubulações. Segundo Amorim et al. (2004), em 85\% dos sistemas, os rejeitos são entornados no solo sem nenhum critério, e em $90 \%$ das formas de despejo, a questão ambiental não está sendo considerada. Souza e Ferreira (2016) trazem a ideia de revender o sal como matéria-prima para indústrias de ração animal, compostos químicos e farmacêuticos, aliando a preocupação ambiental com vantagens econômicas.

Convencionalmente no pré-tratamento da água, são utilizados níveis de aditivos químicos, como cloro e biocidas, para evitar desgastes e desenvolvimento de limo na rede de tubos da usina, resultando em dejetos que, em determinados níveis de concentração, refletem negativamente sobre as populações marinhas (SOUZA; FERREIRA, 2016). Também os impactos relacionados com instalação, operação e localização de usinas 
dessalinizadoras podem vir a ser uma dificuldade, devido a sua instalação em áreas de ecossistemas muito vulneráveis, podendo causar poluição sonora, emissões gasosas e derramamentos químicos (ARRAIA, 2010). A sucção da água também resulta na absorção de organismos aquáticos, afetando, em máximo ou mínimo grau, a fauna marinha, dependendo da velocidade e do volume de água aspirado pela usina (SOUZA; FERREIRA, 2016).

\section{CONCLUSÃO}

Por meio do desenvolvimento da tecnologia para diminuir o consumo energético e para minimizar impactos no meio ambiente, o processo de dessalinização pode ser uma alternativa para assuntos relacionadas à crise hídrica no agronegócio, uma vez que este possibilita a diversificação das atividades agropecuárias e industriais e é uma boa opção para atender à crescente demanda de água, podendo ocasionar uma melhor qualidade de vida a milhões de pessoas, alcançando avanços significativos no procedimento com menor custo, usando matéria-prima mais resistente e menos poluente. A criação de políticas governamentais e o estímulo de investimentos das esferas pública e privada podem amparar as dessalinizadoras quanto à produção agrícola e animal, que aperfeiçoará as obrigações de produzir alta demanda de alimentos para consumir nos anos futuros.

\section{REFERÊNCIAS}

ALI, M. T.; FATH, H. E. S.; ARMSTRONG, P. R. A comprehensive technoeconomical review of indirect solar desalination. Renewable and Sustainable Energy Reviews, v. 15, p. 4187-99, 2011.

AMORIM, M. C. C. et al. Diagnóstico de sistemas de dessalinização de água salobra subterrânea em municípios do estado da Paraíba - Brasil. Congresso Brasileiro de Águas Subterrâneas, 13., 2004.

ARRAIA, E. Dessalinização, você ainda vai beber dessa água. Revista Planeta, v. 455, 2010. Disponível em: https://www.revistaplaneta.com.br/dessalinizacao-voceainda-vai-beber-dessa-agua/. Acesso em: 5 ago. 2018. 
AZEVEDO, C. M. Processo de dessalinização de águas subterrâneas voltado para o agronegócio. Orientadora: Andréa Cristina Santos de Jesus. 2016. 70f. Trabalho de Conclusão de Curso (Graduação em Administração) - Universidade Federal do Rio Grande do Norte, Currais Novos, RN, 2016.

BERTONCINI, E. I. Tratamento de efluentes e reuso da água no meio agrícola. Revista Tecnologia \& Inovação Agropecuária, jun. 2008. Disponível em: https:// www.tratamentodeagua.com.br/wp-content/uploads/2016/06/Tratamento-deefluentes-e-re\%C3\%BAso-da-\%C3\%A1gua-no-meio-agr\%C3\%ADcola.pdf. Acesso em: 21 ago. 2018.

BRASIL. Lei Federal n. 9433, de 8 de janeiro de 1997. Institui a Política Nacional de Recursos Hídricos. Disponível em: http://www.planalto.gov.br/ccivil_03/leis/ L9433.htm. Acesso em: 4 ago. 2018.

BRASIL. Ministério do Meio Ambiente. Caderno setorial de recursos hídricos: saneamento. Brasília: MMA, nov. 2006. Disponível em: http://www.mma.gov.br/ estruturas/161/_publicacao/161_publicacao23022011031657.pdf. Acesso em: 4 ago. 2018.

COOLEY, H.; AJAMI, N.; HEBERGER M. Key issues in seawater desalination in California: marine impacts. California: Pacific Insitute, 2013. Disponível em: http:// pacinst.org/publication/desal-marine-impacts/. Acesso em: 28 ago. 2018.

DUBON, J. A. M.; PINHEIRO, J. C. V. Aproveitamento de águas residuais provenientes de dessalinizadores instalados no estado de Ceará. Ceará: [s.n.], 2001.

FREITAS, T. D. N. Produção de água a bordo de navios e plataformas. Orientador: Bruno Sampaio Andrade. 2011. Trabalho de Conclusão de Curso (Graduação em Tecnologia em Construção Naval) - Centro Universitário Estadual da Zona Oeste (UEZO), Rio de Janeiro, RJ, 2011.

GHAFFOUR, N.; MISSIMER, T. M.; AMY, G. L. Technical review and evaluation of the economics of water desalination: current and future challenges for better water supply sustainability. Desalination, v. 309, 2013.

GLOBAL WATER INTELLIGENCE (GWI). Weekly News, [s.d.]. Disponível em: https:// www.globalwaterintel.com/. Acesso em: 7 ago. 2018.

INTERNATIONAL DESALINATION ASSOCIATION (IDA). 2017. Disponível em: http:// idadesal.org/. Acesso em: 7 ago. 2018. 
INTERNATIONAL RENEWABLE ENERGY AGENCY (IRENA). Water Desalination Using Renewable Energy. Abu Dhabi, 2012. Disponível em: www.irena.org/Publications. Acesso em: 7 ago. 2018.

LARANJEIRA, C. P. F. Estudo numérico dos escoamentos em canais de dessalinização por osmose. Dissertação (Mestrado em Engenharia Civil) - Universidade de Trás-OsMontes e Alto Douro, Portugal, 2010.

MEZHER, T. et al. Techno-economic assessment and environmental impacts of desalination technologies. Desalination, v. 266, 2011.

OLIVEIRA, L. L. P.; OLIVEIRA, T. A.; FARIAS, W. C.; CARDOSO NETO, R.; MEDEIROS, L. C. Efeito da água residuaria de dessalinizadores na germinação de feijão mungoverde. Agropecuária Científica no Semiárido, Campina Grande, v. 9, n. 2, 2013.

OLIVEIRA, T. E.; FREITAS, D. S.; CAMFIELD, L. H. R.; Matheus Dhein DILL. O agronegócio da água. Revista em Agronegócio e Meio Ambiente, Maringá, v. 9, n. 4, p. 785-802, 2016.

ORGANIZAÇÃO DAS NAÇÕES UNIDAS (ONU). Água. 2016. Disponível em: https:// nacoesunidas.org/acao/agua/. Acesso em: 25 jul. 2018.

ORGANIZAÇÃO DAS NAÇÕES UNIDAS PARA ALIMENTAÇÃO E AGRICULTURA (FAO). 2014. Disponível em: http://www.fao.org/news/archive/news-by-date/2014/pt/. Acesso em: 3 ago. 2018.

ORGANIZAÇÃO MUNDIAL DA SAÚDE (OMS). Relatórios Mundiais da Saúde. [S.d.]. Disponível em: http://www.who.int/eportuguese/publications/pt/. Acesso em: 7 ago. 2018.

PEREIRA JÚNIOR, J. S. Dessalinização de água do mar no litoral nordestino e influência da transposição de água na vazão do rio São Francisco. Biblioteca Digital da Câmara dos Deputados, fev. 2005.

PUJATO, A. L. Águas residuais subproduto de dessalinização: uma contribuição ao estado do conhecimento. Orientador: Henio Normando de Souza Melo. 2005. 133 fl. Dissertação (Pós-graduação em Engenharia Sanitária)- Universidade Federal do Rio Grande do Norte (UFRN), Natal, Rio Grande do Norte, 2005.

SILVA, J. F. A. Panorama global da distribuição e uso de água doce e análise de custos de uma planta de osmose reversa acionada com diferentes fontes de energia. 
Orientador: Roberto Guimarães Pereira. 2015. 237 fl. Dissertação (Mestrado em Sistemas de Gestão)- Universidade Federal Fluminense, Niterói, RJ, 2015.

SOUZA, L. F. Dessalinização como fonte alternativa de água potável. Norte Científico, Boa Vista, v. 1, n. 1, 2006.

SOUZA, L. H. V.; FERREIRA, L. C. Energias renováveis e segurança hídrica: a energia termossolar como alternativa para a dessalinização da água do mar no Norte da África e Oriente Médio. Sustentabilidade em Debate, Brasília, v. 7, n. 1, p. 15-28, jan./abr. 2016.

THOMAS, J. S.; DURHAM, B. Integrated water resource management: looking at the whole picture. Desalination, Malta, v. 156, p. 2I-28, 2003.

VEOLIA. Dessalinização de Água do Mar. [S.d]. Disponível em: http://www. veoliawatertech.com/latam/pt/mercados/municipal/dessalinizacao/. Acesso em: 5 ago. 2018.

ZAMBERLAN, J. F. et al. Análise de benefício- custo levando-se em consideração os custos da água de irrigação para o arroz. Tecno-Lógica, Santa Cruz do Sul, v. 15, n. 2, p. 100-4, 2011. 
